\title{
Progress on new vaccine strategies for the immunotherapy and prevention of cancer
}

\author{
Jay A. Berzofsky, ${ }^{1}$ Masaki Terabe, ${ }^{1}$ SangKon Oh, ${ }^{1}$ Igor M. Belyakov, ${ }^{1}$ Jeffrey D. Ahlers, ${ }^{2}$ \\ John E. Janik, ${ }^{3}$ and John C. Morris ${ }^{3}$
}

\begin{abstract}
${ }^{1}$ Molecular Immunogenetics and Vaccine Research Section, Vaccine Branch, Center for Cancer Research (CCR), National Cancer Institute (NCI), 2Division of AIDS, National Institute of Allergy and Infectious Diseases, and ${ }^{3} \mathrm{Clinical}$ Trials Team, Metabolism Branch, CCR, NCI, NIH, Bethesda, Maryland, USA.
\end{abstract}

\begin{abstract}
In recent years, great strides in understanding and regulating the immune system have led to new hope for harnessing its exquisite specificity to destroy cancer cells without affecting normal tissues. This review examines the fundamental immunologic advances and the novel vaccine strategies arising from these advances, as well as the early clinical trials studying new approaches to treat or prevent cancer.
\end{abstract}

Despite multiple approaches to therapy and prevention, cancer remains a major cause of death worldwide. Most nonsurgical approaches targeting rapidly dividing cells, using radiotherapy or chemotherapy, also affect normal cells and result in side effects that limit treatment. In principle, the exquisite specificity of the immune system could be marshaled to precisely target cancer cells without harming normal cells. This hope has motivated much research over several decades but has met with only limited success to date. However, the rapid increase in knowledge of the immune system and its regulation have led to a resurgence of interest in immunologic approaches to target and eliminate cancer (1-7).

A major difference between microbial pathogens and tumors as potential vaccine targets is that cancer cells are derived from the host, and most of their macromolecules are normal self-antigens present in normal cells. To take advantage of the immune system's specificity, one must find antigens that clearly mark the cancer cells as different from host cells $(1,2)$, limiting the number of antigens available. Additionally, many potential tumor antigens are not expressed on the surface of tumor cells and thus are inaccessible to antibodies.

The immune system has evolved a solution to this problem: the MHC antigens (HLA molecules in humans) that act as an internal surveillance system to detect foreign or abnormal proteins made inside the cell (Figure 1) (8, 9). A sampling of all proteins synthesized in the cell is cleaved by proteasomes into short fragments (peptides) that are transported into the endoplasmic reticulum. There, the peptides are loaded onto newly synthesized class I MHC molecules, such as HLA-A, -B, and -C. The peptide-MHC complexes are transported to the cell surface for recognition by the $\mathrm{T}$ cell receptors (TCRs) of $\mathrm{CD}^{+} \mathrm{T}$ lymphocytes, such as CTLs. Thus, CTLs recognize short peptides, 8-10 amino acid residues in length, arising from the proteasomal degradation of intracellular proteins and able to bind to class I HLA molecules. For this reason, CTLs are not limited to tumor antigens expressed intact on the

Nonstandard abbreviations used: carcinoembryonic antigen (CEA); complete response (CR); enzyme-linked immunoabsorbent spot (ELISPOT); influenza matrix peptide (FMP); human papillomavirus (HPV); idiotype (Id); incomplete Freund's adjuvant (IFA); natural killer T (NKT); oligodeoxynucleotide (ODN); prostatic acid phosphatase (PAP); partial response (PR); prostate-specific antigen (PSA); prostatespecific membrane antigen (PSMA); T cell receptor (TCR).

Conflict of interest: The authors have declared that no conflict of interest exists.

Citation for this article: J. Clin. Invest. 113:1515-1525 (2004).

doi:10.1172/JCI200421926. cell surface but can detect any abnormal protein synthesized in the cell, greatly expanding the range of tumor antigens detectable by the immune system. Furthermore, CTLs play an important role in the rejection of transplanted organs and tissues (10), analogous to tumors as foreign or abnormal human cells invading the host. Thus, although monoclonal antibodies have clearly shown therapeutic efficacy in certain cancers (e.g., trastuzumab, rituximab, alemtuzumab) (11), most cancer vaccine strategies have focused on induction of CTLs that lyse tumor cells. Recent understanding of the mechanisms of activation and regulation of $\mathrm{CD}^{+} \mathrm{T}$ cells has given new life to tumor immunology. Notwithstanding the critical role of $\mathrm{CD}^{+} \mathrm{T}$ cells, induction of tumor-specific $\mathrm{CD}^{+} \mathrm{T}$ cells is also important not only to help $\mathrm{CD}^{+}$responses, but also to mediate antitumor effector functions through induction of eosinophils and macrophages to produce superoxide and nitric oxide (12).

For naive $\mathrm{CD}^{+} \mathrm{T}$ lymphocytes to be activated initially, or "primed," they generally require presentation of antigens by professional APCs, such as DCs (13). DCs express high levels of costimulatory molecules, such as CD80 and CD86, which can make the difference between turning off the CTL precursor and activating it. DCs also secrete critical cytokines such as IL-12 and IL-15 that contribute to CTL activation and memory. In addition, a number of regulatory mechanisms that dampen the immune response are exploited by tumors to escape immunosurveillance. These mechanisms include the inhibitory receptor CTLA-4 on the T cells themselves (14) and negative regulatory cells such as the $\mathrm{CD} 25^{+} \mathrm{CD} 4^{+}$regulatory $\mathrm{T}$ cell (15-17) and also certain types of $\mathrm{CD}^{+}{ }^{+}$natural killer $\mathrm{T}$ (NKT) cells that inhibit tumor immunosurveillance (4, 17-19).

Major hurdles in developing cancer vaccines include: identification of antigens that focus the exquisite specificity of the immune system on cancer cells without harming normal cells; development of methods to induce an immune response sufficient to eradicate the tumor, in the face of self-tolerance to many tumor antigens; and overcoming mechanisms by which tumors evade the host immune response.

\section{Types of tumor antigens}

An extensive listing of the known tumor-associated antigens is available, and more are being discovered (20). Tumor antigens can be categorized into four groups: (a) antigens unique to an individual patient's tumor; (b) antigens common to a histologically similar group of tumors; (c) tissue-differentiation antigens; and (d) ubiquitous antigens expressed by normal and malignant cells. These cat- 


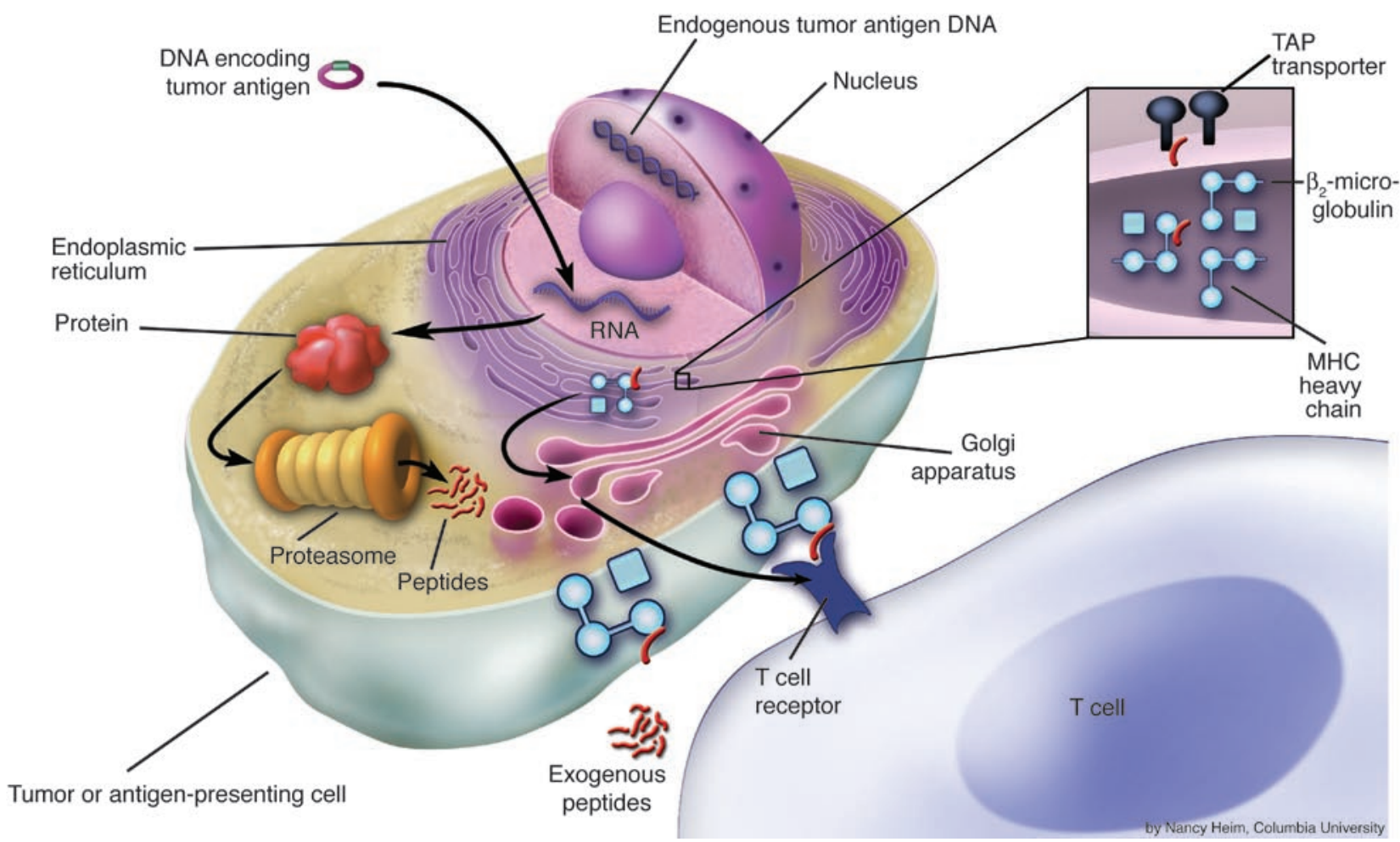

\section{Figure 1}

The class I MHC antigen processing pathway acting as an internal surveillance mechanism to detect any abnormal or foreign protein synthesized in the cell. Tumor antigens encoded in the endogenous DNA of the tumor cell, or encoded in a DNA plasmid or viral vector vaccine taken up by an APC, are synthesized and cleaved by the $26 \mathrm{~S}$ proteasome into fragments that are transported by TAP, the transporter associated with antigen processing, into the endoplasmic reticulum, where they are loaded onto newly synthesized class I MHC molecules that transport them to the cell surface for recognition by the T cell receptor.

egories and the two major strategies used to identify tumor antigens are described in Approaches to tumor antigen discovery.

To specifically target tumors, antigens must be expressed only in tumor cells. Such unique tumor antigens (21) include mutated proteins, such as mutated oncoprotein ras (22) and mutated tumor suppressor proteins p53 $(21,23)$ and von Hippel Lindau; and fusion proteins created by chromosomal translocations, such as BCR-ABL in chronic myelocytic leukemia (24), PAX-FHKR in alveolar rhabdomyosarcoma (25), EWS-FLI1 in Ewing sarcoma (26), and SYT-SSX in synovial sarcoma (27). K-ras mutations occur in $30-40 \%$ of colorectal carcinomas (28), and mutations of p53 are found in $60-70 \%$ of all human cancers (29). Peptides derived from common ras mutations bind to specific $\mathrm{MHC}$ molecules and can generate tumor-specific immune responses $(30,31)$. Because the mutations are necessary for generation and maintenance of the neoplastic phenotype, they are expressed by all of the tumor cells and cannot be lost. However, only a short segment of the amino acid sequence encompassing the mutation or fusion breakpoint is actually unique, and this region may not be presented by many common HLA molecules. Another type of tumor antigen unique to cancer cells are antigens with tumor-specific posttranslational modifications, exemplified by MUC1, which shows altered glycosylation in cancer cells, creating neoantigenic sites by exposing protein sequences normally masked by glycosylation $(1,7)$.

To overcome this problem, investigators have searched for whole proteins either not highly expressed in adult tissues, such as carcinoembryonic antigen (CEA) $(32,33)$; overexpressed in can- cer cells, such as nonmutated portions of p53 (34); or uniquely expressed in expendable tissues. The latter include melanocyte antigens gp100, MART1, or tyrosinase in melanoma (3) and prostate-specific antigen (PSA) or prostate-specific membrane antigen (PSMA) in prostate cancer (35). The disadvantage is that self-tolerance may limit responses to these normal host proteins. Expression of these proteins can also be lost if they are not essential for malignancy, allowing tumor escape. The most foreign tumor antigens are viral proteins, such as human papillomavirus-16/18 (HPV-16/18) E6 and E7 oncoproteins in cervical cancer (7) or EBV proteins in certain B cell malignancies (36). In the case of HPV, these E6/E7 proteins are essential for malignant transformation and so cannot be lost to escape the immune response.

\section{Cancer vaccine modalities}

The vaccine strategies used against cancer depend on how well defined the target antigens are and whether there are conserved antigens that are shared among tumors of the same type in many individuals. We will discuss the rationale for, and experience with, some of the most widely studied approaches (Table 1).

\section{Modified tumor cell vaccines}

The richest source of rejection antigens is the tumor itself. However, use of autologous tumor cell vaccines is cumbersome and not amenable to large-scale vaccine production, and tumor samples are often unavailable. Approaches using allogeneic or generic cell lines as vaccines are more widely applicable. 


\section{Based on existing host response}

Identify tumor-reactive T cells or antibodies from patients; use to screen tumor libraries

T cells may be tumor-infiltrating lymphocytes (TILS) or peripheral blood T cells

Advantages: Antigen known to be immunogenic

Disadvantages: Limited to tumors that are immunogenic

Limited to antigens that induce a response without active immunization

Not always possible to identify the antigen

Antigen may not be unique to tumor

\section{Based on tumor characterization (what is different)}

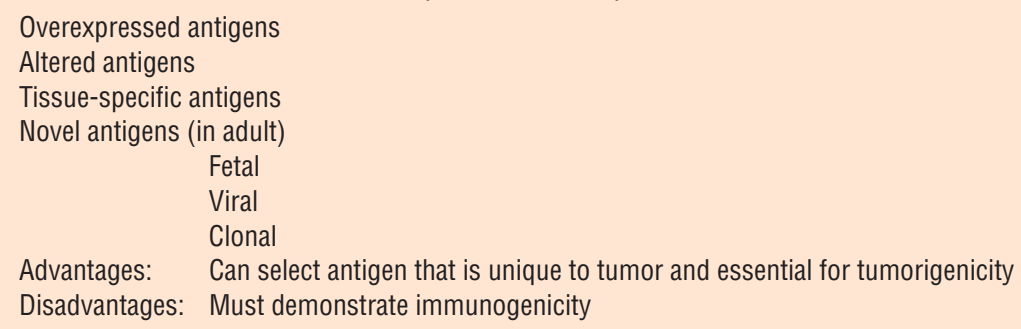

\section{Examples}

gp100, MAGE, MART-1

Examples

HER-2/neu, CEA

p53, Ras, fusion proteins tyrosinase, PSA

CEA

HPV E6, E7

Idiotype
Tumor cells engineered to secrete a number of different cytokines have been shown to protect mice from challenge with the same tumor type (37). Of the cytokines studied, GM-CSF appeared most effective. Local expression of GM-CSF increases DCs and other APCs at the site of injection of vaccination. These acquire, process, and present antigen to T cells. A number of genetically modified autologous or allogeneic tumor cell vaccines have been tested in clinical trials (38-41). Studies in patients with advanced prostate cancer (38) and metastatic malignant melanoma (39) used irradiated autologous tumor cells transduced with a retroviral vector expressing GM-CSF, resulting in one partial response in 21 melanoma patients, although extensive inflammatory infiltrate with necrosis and fibrosis of tumor was seen in 11 of 16 melanoma patients biopsied (39). In another phase I trial, among 14 patients with resectable pancreatic cancer vaccinated with GM-CSF-transduced allogeneic pancreatic cancer cell lines after surgery (40), three patients remained disease free at 23 months. A number of other genetically altered autologous and allogeneic tumor cell vaccines expressing IL-2, IL-4, B7.1, and $\alpha-(1,3)$ galactosyltransferase are currently in clinical trials (42-44).

\section{Peptide vaccines}

Elucidation of the crystal structure of the MHC and of the peptides bound to it (45) and discovery of anchor-residue sequence motifs accounting for binding specificity of peptides to MHC molecules (46) has provided the visual and mechanistic answer to how T cells recognize antigens in the form of short peptides. The observation that short peptide segments (8-10 amino acids) fit into a groove in the MHC molecule, combined with knowledge of the amino acid sequences of tumor epitopes, prompted the use of peptides as therapeutic agents in the treatment of cancer. These observations were followed by cloning of the first human tumor-associated antigen and identification of its nonamer peptide sequence (47). Several strategies have been developed both to improve immunogenicity and to steer the immune system toward desired types of responses. Also, peptides have been loaded onto autologous DCs for administration, as described below. However, individual peptides will be useful only in patients with appropriate HLA molecules capable of presenting that peptide.
Epitope enhancement. Modification of the amino acid sequence of epitopes, commonly referred to as epitope enhancement, can improve the efficacy of vaccines through several means: (a) increasing affinity of peptide for MHC molecules (4, 48, 49); (b) increasing TCR triggering $(32,33,50)$; or (c) inhibiting proteolysis of the peptide by serum peptidases $(4,6,51)$. Whenever the peptide sequence is altered, it is important to demonstrate that the T cells induced still recognize the native peptide sequence. There is precedent for epitope-enhanced peptides showing greater efficacy in clinical trials (49) (see below).

Cytokines, chemokines, and costimulatory molecules as adjuvants. Another approach is to deliver the peptide with adjuvants containing cytokines, chemokines, costimulatory molecules, or other immunomodulators that amplify and direct the immune response (4). Th1 $\mathrm{CD}^{+} \mathrm{T}$ cells and $\mathrm{CD}^{+}{ }^{+}$cytotoxic $\mathrm{T}$ cells crucial for antitumor immunity are induced more efficiently by professional APCs, such as DCs. Based on this knowledge, a recent strategy for the development of peptide vaccines uses a synergistic combination of cytokines that induce DC recruitment (GM-CSF) and costimulatory molecules that induce DC maturation (CD40L or agonistic anti-CD40) (52) in combination with other Th1/CTLsupporting cytokines such as IL-12 and IL-15. Other synergistic combinations have been described in animal models (4). Another adjuvant, a CpG-oligodeoxynucleotide (CpG-ODN), characteristic of bacterial DNA, is used to elicit a broad range of immune cells (53). Differences between humans and mice in the response to cytokines such as GM-CSF and expression of the toll-like receptor 9 (TLR9) for CPG-ODN on DCs will require confirmation during the testing of these approaches in clinical trials. Another approach to target DCs is to use ex vivo-generated DCs that have been preincubated (pulsed) with the peptide of interest. Using peptides with broad MHC class II binding such as pan-HLA-DR-binding peptide (PADRE) (54), endogenous helper epitopes $(55,56)$, or enhanced helper epitopes (57) to stimulate $\mathrm{CD}^{+} \mathrm{T}$ cell help also results in increased $\mathrm{CD}^{+} \mathrm{T}$ cell responses.

Clinical trials of peptide vaccines. The best-studied clinical model of peptide vaccination is malignant melanoma. The various immunologic monitoring methods employed are listed in Table 2. Each 
has advantages and disadvantages, but none has been shown to provide a surrogate marker for tumor prevention or regression.

Rosenberg and colleagues evaluated vaccination with native gp100 peptide 209-217 and found that it produced only low levels of T cell reactivity in two of eight melanoma patients analyzed, whereas an epitope-enhanced gp100 (g209-2M) peptide generated strong T cell reactivity in 10 of 11 patients immunized (49). Nevertheless, only a single objective clinical response was reported. Immunization with g209-2M, combined with high dose IL-2 treatment, produced antitumor responses in $42 \%$ of patients, although $\mathrm{T}$ cell reactivity was observed in less than $10 \%$ of patients. In the adjuvant setting, Smith et al. (58) found a vaccination frequency of every two or three weeks resulted in a median frequency of $\mathrm{CD} 8^{+}$cells binding g209-2M tetramers of $0.34 \%$ after 6 months, compared with $0.02 \%$ before vac- cination, whereas less frequent vaccination gave substantially lower responses of $0.03 \%$. Addition of either IL-12 (59) or GM-CSF (60) increased this percentage slightly. The impact of age was striking (58). In patients under 60 years old, the median number of tetramerpositive $\mathrm{CD}^{+}$cells induced by vaccination was $0.64 \%$, whereas in those over 60 it was $0.08 \%$.

Immunization with tyrosinase peptide has been significantly less effective despite epitope enhancement. Immunization with the tyrosinase $370 \mathrm{D}$ peptide in incomplete Freund's adjuvant (IFA) with or without cytokines, including IL-12 (59) or GM-CSF (60), only rarely resulted in low numbers of tetramer-positive CD8 cells or cytokine production. The levels of 370D-responsive cells detected by enzyme-linked immunoabsorbent spot (ELISPOT) assay have been low (0.01-0.03\% of input cells) (61). The use of

\section{Table 1}

Antitumor vaccines in clinical trials

\section{Vaccine}

Whole tumor cell

Gene-modified tumor cells

Peptides

Viral gene transfer vectors

Antigen-modified DCs

\section{Advantages}

1. Studied extensively

2. Can be processed to enhance antigen presentation

(e.g., irradiated tumor cells or tumor lysates);

3. Can be administered with adjuvants

(e.g., BCG, KLH, viruses, etc.);

4. Likely to express the relevant tumor antigens;

5. Antigens need not be defined

1. Likely to express the relevant tumor antigens;

2. Antigens need not be defined;

3. Often engineered to coexpress immunostimulatory molecules and cytokines (e.g., GM-CSF, IL-2);

4. Use of allogeneic tumor cell lines and fibroblasts are under investigation as an approach to accelerate vaccine production;

5. Some immunological and clinical responses reported

1. Constructed to express the relevant tumor antigen;

2. Easy to produce and stable;

3. Can be administered as a direct injection or biolistically ("gene gun")

1. Can limit immune response to epitopes distinct from the 1. Requires knowledge of the specific epitope; wild type (e.g., point mutations or breakpoint-fusion genes); 2. Immunogenicity restricted to a limited number 2. Epitopes can be enhanced;

3. Easy to produce and stable;

4. Can be combined as cocktails of peptides;

5. Some immunological and clinical responses reported

1. Engineered to express the relevant tumor antigen;

2. Can be engineered to coexpress immunostimulatory molecules and cytokines;

3. Wide variety of available vectors (e.g., adenovirus, pox viruses, lentiviruses, etc.);

4. Some cellular immune responses reported

1. Use of powerful APCs;

2. Techniques available to generate large numbers of clinical grade DCs;

3. Target antigens may be defined or uncharacterized;

4. Multiple antigen loading techniques (e.g., peptide, lysates, whole protein, RNA transfection, viral vectors, etc.) are available;

5. Some immunological and clinical responses reported

\section{Disadvantages}

1. Requires availability of autologous tumor or an allogeneic cell line sharing the relevant tumor antigens;

2. Poor ability to stimulate immune responses;

3. Few responses and little benefit

reported when used adjuvantly in randomized clinical trials

1. Requires availability of autologous tumor or an allogeneic cell line expressing the relevant tumor antigens;

2. Weak antigen presentation by many tumors;

3. Long manufacturing time;

4. Need for ex vivo cell culture;

5. Cost, time, and labor intensive

1. Requires detailed knowledge of the antigen DNA sequence;

2. Low immunological potency for self (tumor) antigens;

3. Response may be Th2 skewed;

4. High doses of plasmid DNA are required to generate immune responses

of MHC molecules;

3. Usually requires the addition of an adjuvant for immunogenicity

1. Immunodominance of viral antigens over tumor antigens;

2. Weak antitumor responses seen with most viral vectors;

3. Preexisting immunity against viral vectors may attenuate

the antitumor response;

4. Risk of toxicity with "live" viruses

1. Need for ex vivo cell culture;

2. Cost, time, and labor intensive;

3. Optimal technique for antigen loading remains undefined;

4. Possibility of tolerization by immature DCs;

5. Lack of criteria for standardization of final product 
Table 2

Immune response monitoring for clinical trials

\begin{tabular}{|c|c|c|c|}
\hline Assay & Advantages & Disadvantages & Sensitivity \\
\hline Proliferation & Technically simple & $\begin{array}{l}\text { Unable to enumerate specific cells; measures } \\
\text { predominantly CD4, not CD8, T cells }\end{array}$ & \\
\hline Tetramer staining & $\begin{array}{l}\text { Quantitative cell number; } \\
\text { subset analysis possible }\end{array}$ & $\begin{array}{l}\text { Requires synthesis of specific tetramers; not a measure } \\
\text { of functional activity; limited to single epitopes }\end{array}$ & $1: 10^{4}$ \\
\hline $\begin{array}{l}\text { Cytokine flow } \\
\text { cytometry }\end{array}$ & $\begin{array}{l}\text { Quantitative cell number; functional } \\
\text { assay; subset analysis possible }\end{array}$ & $\begin{array}{l}\text { Requires incubation; unable to obtain live cells } \\
\text { after assay; technically complicated }\end{array}$ & $1: 5 \times 10^{4}$ \\
\hline ELISA & Functional assay & $\begin{array}{l}\text { No phenotypic information on responding cells; unable } \\
\text { to enumerate specific cells; bystander activation }\end{array}$ & \\
\hline ELISPOT & $\begin{array}{l}\text { Quantitative cell number; } \\
\text { functional assay }\end{array}$ & $\begin{array}{l}\text { No phenotypic information on responding } \\
\text { cells; bystander activation }\end{array}$ & $1: 10^{5}$ \\
\hline Cytotoxicity & $\begin{array}{l}\text { Functional assay; } \\
\text { relative cell quantitation }\end{array}$ & $\begin{array}{l}\text { Requires autologous tumor/targets; in vitro stimulations } \\
\text { required; unable to enumerate specific cells }\end{array}$ & \\
\hline RT-PCR & $\begin{array}{l}\text { Universal reagents; } \\
\text { indirect measure of function }\end{array}$ & $\begin{array}{l}\text { Measures mRNA, not protein; unable to enumerate specific cells; } \\
\text { requires several steps (time consuming) }\end{array}$ & $1: 10^{5}$ \\
\hline Limiting dilution & $\begin{array}{l}\text { Quantitative cell number; } \\
\text { functional assay }\end{array}$ & $\begin{array}{l}\text { Labor intensive; requires multiple stimulations; } \\
\text { detects only cells that can proliferate }\end{array}$ & $1: 10^{5}$ \\
\hline
\end{tabular}

peptide vaccines may be additionally complicated by the choice of adjuvants. Most studies used IFA, but in the study by Schaed et al. (61), patients showed no response with $370 \mathrm{D}$ peptide in IFA, whereas almost $50 \%$ of patients showed low-level ELISPOT responses with QS21 or GM-CSF as adjuvants.

The importance of epitope enhancement is supported by the promising results of vaccination with the epitope-enhanced carcinoembryonic antigen (CEA) peptide (33). FLT3 ligand-expanded DCs were pulsed with this peptide to immunize patients with advanced colorectal cancer. Five of 12 patients immunized developed greater than $1 \%$ tetramer-positive $\mathrm{CD}^{+} \mathrm{T}$ cells, and two showed clinical responses.

Despite the small sample sizes and the variable populations treated, some principles emerge. Immunization with native peptide sequences is often insufficient to generate reactive $T$ cells and clinical responses in most patients. Epitope-enhanced peptides can generate $\mathrm{T}$ cell responses but not always clinical tumor responses. Adjuvants, including cytokines and costimulatory molecules, improve the immunogenicity of peptide vaccination. Paradoxically, combining peptide vaccination with IL-2 significantly reduced detection of specific $\mathrm{T}$ cells in blood, but nearly half the patients showed objective cancer regressions (49), possibly due to IL-2-induced innate immunity combined with vaccine immunity. In a new approach, blockade of the negative regulatory molecule CTLA-4 showed promise when combined with vaccination with g209-2M in melanoma patients. Three of 14 patients treated had objective tumor regressions although at the cost of development of autoimmune disease, including bowel, liver, and pituitary dysfunction (62). Blockade of other negative regulatory pathways has shown promise in animal models $(4,16,18)$.

\section{Recombinant viral vectors}

A number of trials utilizing recombinant viruses expressing tumor antigens such as CEA or PSA, some with immunostimulatory cytokines, have been reported or are in progress $(63,64)$. Adenovirus, vaccinia, and avipox vectors have been used. The high prevalence of antiviral neutralizing antibodies may limit use of these vectors, especially for multiple doses, except for fowlpoxes (e.g., the canarypox virus vector ALVAC) that do not appear to induce neutralizing antibodies. Possible resistance due to prior systemic immunity to poxviruses can potentially be overcome by mucosal immunization, because systemic immunization is poor at inducing mucosal immunity, but mucosal immunization can induce both systemic and mucosal immunity (65). Immunodominance is also problematic. Stronger immune responses may be induced against viral vector antigens than against weaker tumor antigens. The potency of these vectors may be enhanced by the addition of genes for immunostimulatory molecules or cytokines $(66,67)$. Such vectors are entering clinical trials. These vectors can also be used to express antigens in DCs, as described below.

\section{DNA vaccines}

Intramuscular injections of naked DNA expression plasmids have been shown to generate immune responses $(68,69)$. Such DNA vaccines introduce tumor antigen genes into DCs for endogenous processing and presentation to CTLs in draining lymph nodes or into other cells for cross-presentation by DCs, without the need for a viral vector (Figure 2). Thus, problems of competition from viral vector epitopes, reduced efficacy due to prior immunity to the viral vector, and potential dangers associated with a live virus are avoided. Constitutive, tissue, or tumor-specific promoters may be used for selective expression.

The results of a number of plasmid DNA vaccine trials have been reported. Among 12 patients with follicular lymphoma vaccinated with plasmids encoding tumor-specific idiotypes (70), four mounted a humoral anti-idiotype or a specific anti-idiotype $T$ cell proliferative response. In another trial, among 17 patients with metastatic colorectal carcinoma vaccinated with a plasmid encoding both CEA and hepatitis B surface antigen (HBs) as a control (71), six developed protective levels of anti-HBs antibody, but none developed antibody to CEA, although 4 of 17 developed a lymphoproliferative response to CEA. Thus, DNA vaccines have not yet shown much promise for antitumor vaccination. 


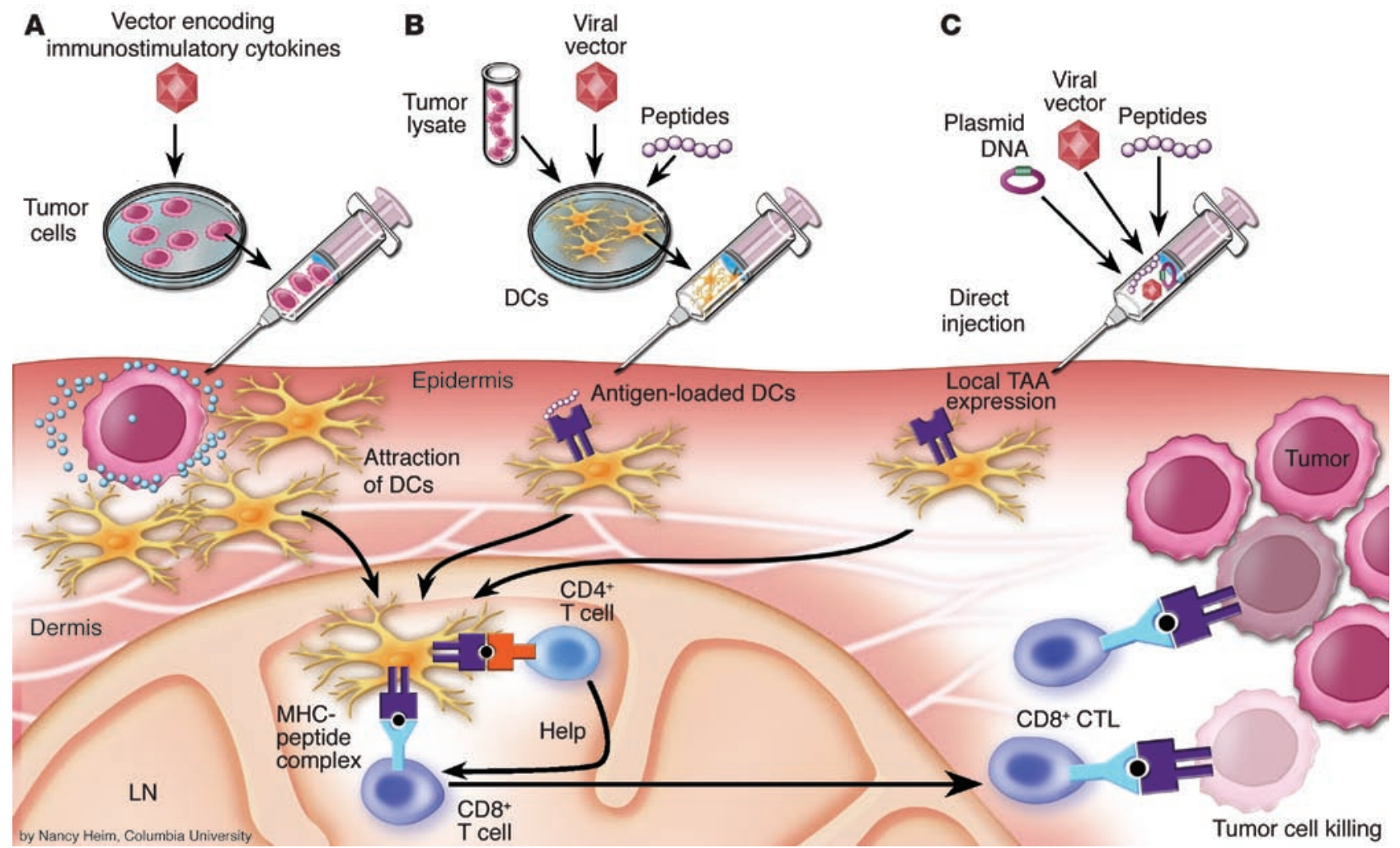

Figure 2

Approaches to antitumor vaccination. (A) Irradiated tumor cells transduced with a viral gene transfer vector encoding a cytokine such as GM-CSF attract APCs (DCs) that acquire, process, and present tumor-associated antigens (TAAs) encoded by the vector in the context of MHC. (B) DCs can be directly loaded by incubation with tumor protein lysates or peptides with sequences based on expressed tumor antigens, or by viral gene transfer vectors expressing TAAs. (C) TAAs can be locally supplied to DCs by the direct injection of peptides, viral gene expression vectors, or naked DNA expression plasmids. DCs migrate to secondary lymphoid tissues where they present the antigen epitopes to $T$ cells to generate an antitumor cytolytic $T$ cell response.

\section{Dendritic cell vaccines}

DCs are professional APCs and are the most powerful stimulators of naive $T$ cells $(13,72,73)$. Immature DCs sample the antigenic environment through phagocytosis, micropinocytosis, receptorand lectin-mediated endocytosis and are more effective at processing antigen. When DCs encounter inflammatory mediators such as bacterial LPS, or TNF- $\alpha$, they mature. Helper T cells also induce DC maturation via CD40 ligand interaction with CD40. As they mature, DCs downregulate their antigen uptake and processing machinery; express CD83; upregulate $\mathrm{MHC}$, costimulatory molecules (CD80 and CD86), and the chemokine receptor CCR7; and travel to lymph nodes where they activate antigen-reactive $T$ cells.

Demonstration of acquired defects in DC maturation and function in tumor-bearing animals and cancer patients suggests a rationale for using ex vivo-generated DCs as antitumor vaccines. Gabrilovich and colleagues reported ineffective CTL induction in a murine mutant p53 fibrosarcoma model associated with defects in DC function (74). Supernatants from tumor cells suppressed DC maturation, ultimately attributed to an effect of VEGF (75). In contrast, DCs generated in vitro from marrow progenitors stimulated allogeneic $T$ cells and induced mutant $\mathrm{p} 53$ peptidespecific $T$ cell responses $(74,76,77)$. Immunization with mutant p53-peptide-pulsed DCs inhibited the growth of established tumors in the mice.
DCs pulsed with tumor lysates (78), tumor protein extracts (79-81), synthetic peptide tumor epitopes $(74,82)$, or DCs fused with irradiated tumor cells (83) could generate protective immunity to subsequent tumor challenge. Transfer of nucleic acids encoding tumor antigens into DCs using plasmid transfection (84), retroviral vectors (85), recombinant adenoviruses (86), lentiviruses (87), or electroporation of tumor RNA (81) has been effective. Antigens can also be targeted to DCs by coupling to DC-specific antibodies (88). Transfer of genes encoding costimulatory molecules (B7) and cytokines (IL-12) into DCs has also enhanced antitumor vaccine efficacy (80).

Clinical trials of DC vaccines have depended on development of techniques for obtaining large numbers of clinical grade human DCs $(89,90)$. Currently, two general approaches are used: (a) purification of immature DC precursors from peripheral blood (72); and (b) ex vivo differentiation of DCs from $\mathrm{CD} 34^{+}$hematopoietic progenitor cells $(91,92)$ or peripheral blood monocytes $(90)$, commonly by culture of monocytes with GM-CSF and IL-4 (Figure 3). Immature DCs can be matured with CD40 ligand, LPS, or TNF- $\alpha$ (93). In mice, CD40 ligand-mediated maturation was the most effective approach for DC vaccine preparation (94).

In humans, the finding that two healthy volunteers receiving immature DCs pulsed with influenza matrix peptide (FMP) had a reduction in FMP-specific $\mathrm{CD}^{+} \mathrm{T}$ cell activity (95) raised concerns 


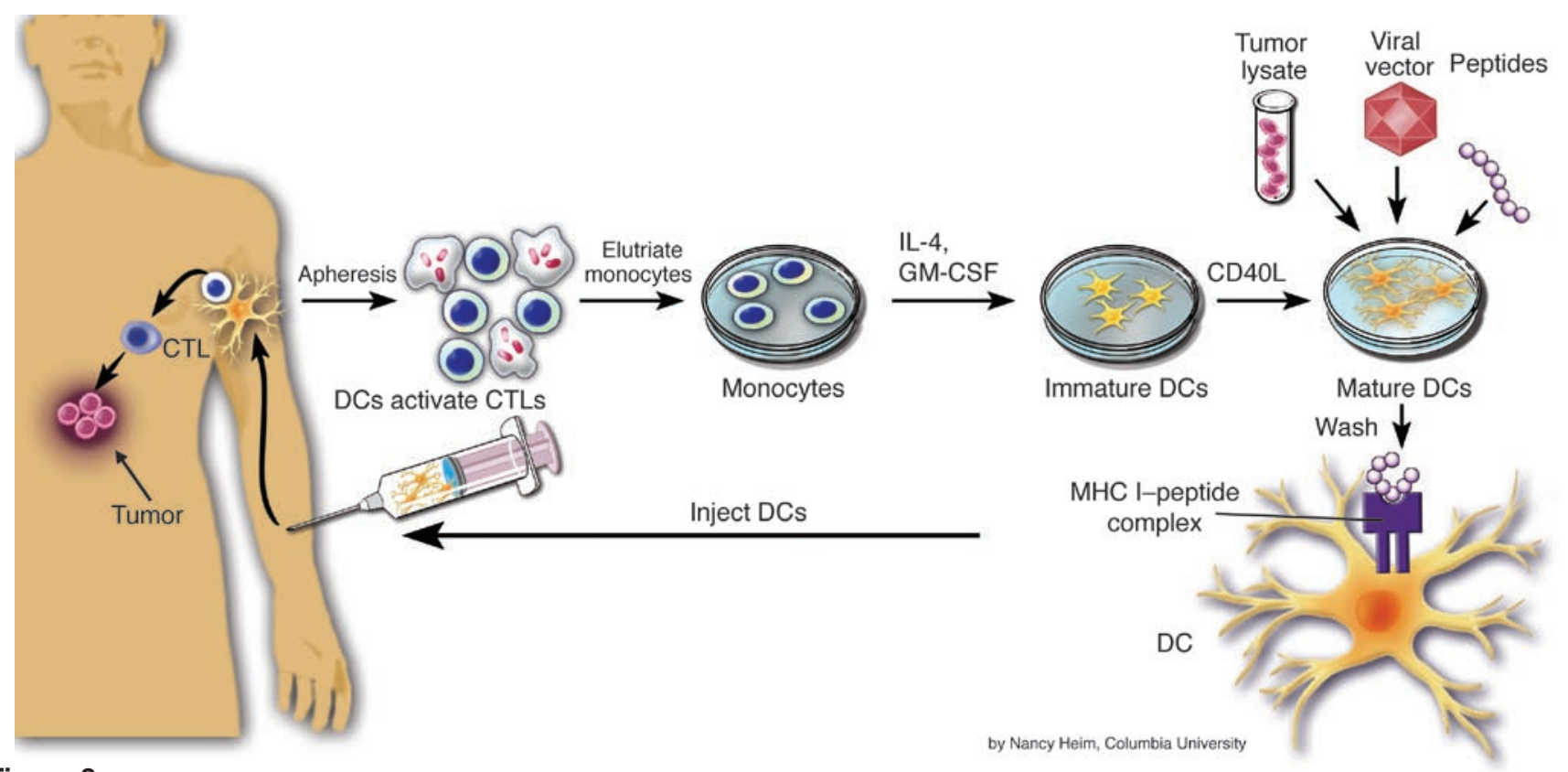

Figure 3

Generation of antitumor DC vaccines from peripheral blood monocytes. Elutriated monocytes from a leukapheresis are cultured with GM-CSF and IL-4 to produce DCs, which are then matured with CD40 ligand (CD40L) or other agents, pulsed with peptide or tumor lysate, or transduced with an expression vector and then injected into the patient as an autologous DC vaccine to induce a T cell immune response against the tumor.

that immature DCs might induce tolerance to antigens $(96,97)$. The recent trend has been to use DCs matured using TNF- $\alpha$, CD 40 ligand, monocyte-conditioned media, or cytokine cocktails $(98,99)$.

Clinical trials of anticancer DC vaccines. A number of DC cancer vaccine trials have been reported. Hsu et al. reported the first DC vaccine trial for treatment of cancer in patients with follicular B cell lymphomas (100), which express a unique clonal B cell receptor (idiotype, Id) that can distinguish lymphoma cells from nonmalignant lymphocytes. Initially, ten patients were treated with peripheral blood DCs pulsed with a tumor-specific Id protein. Eight developed Id-specific cellular proliferative responses, and one developed a specific CTL response. Two patients had complete responses (CRs), one a partial response (PR), and another a complete molecular response. A follow-up study with an additional 25 patients found that 15 of 23 generated $\mathrm{T}$ cell and humoral anti-Id responses (101).

Multiple myeloma (plasma) cells also express unique clonal immunoglobulin idiotypes (102-104) but do not express Id protein on the cell surface, instead producing large amounts for secretion. Myeloma cells can still be detected by CTLs that recognize Id peptides presented by HLA molecules. Of 26 patients treated with Id-pulsed DCs after high-dose chemotherapy and stem cell transplantation, four developed Id-specific $\mathrm{T}$ cell proliferative responses. Although the stem cell transplant itself produced 5 CRs and 21 PRs, 8 patients with PRs had further declines in their serum monoclonal spike after the DC vaccination, and of the four patients that developed an immune response, two remained in CR at 35 and 28 months after transplantation (103). In another trial (104), patients with residual low-volume myeloma after transplant were immunized with DCs pulsed with autologous serum as a source of Id. Of the 13 evaluable patients, three achieved a CR and 3 a PR.

DC vaccines have also been studied in patients with solid tumors. Of 21 patients with recurrent or metastatic prostate cancer and elevated serum prostatic acid phosphatase (PAP) treated with DCs pulsed with rodent PAP, ten developed T cell-proliferative responses to PAP (105). Among 16 patients with metastatic melanoma receiving peptide- or tumor lysate-pulsed DCs injected directly into lymph nodes, eleven developed delayed-type hypersensitivity responses to peptide-pulsed DCs, and two had durable CRs (106). Among 11 melanoma patients receiving monocyte-derived DCs pulsed with HLA-A1-restricted MAGE-3 melanoma peptide, eight developed a CTL response, and some minor tumor regressions were observed (107). Recently, 20 patients with advanced pancreatic, hepatocellular, cholangiocarcinoma, or medullary thyroid carcinoma were treated with monocyte-derived DCs pulsed with tumor lysates, matured with TNF- $\alpha$, and administered along with daily subcutaneous IL-2 (108). Although 18 of 20 patients developed DTH responses and 8 had a decline in serum tumor markers, no CRs or PRs were seen. A small, uncontrolled clinical trial in metastatic renal cell carcinoma with tumor RNA-loaded DCs reported an unusually low mortality from tumor in the follow-up period (109).

Inconsistency in trial results may relate to several variables, including the type and quality of DCs that vary with method of generation and maturation, the technique used for epitope loading, and the dose, route, and frequency of vaccination. Animal models indicate benefit of multiple vaccinations compared to a single dose (74) and of subcutaneous and intradermal administration (110). Thus, while the use of DCs as a vehicle for therapeutic cancer vaccination holds promise to circumvent some strategies tumors use to evade the immune system, there are still many technical issues to be resolved in this approach, which needs to be compared directly with other vaccine modalities.

\section{Future strategies to enhance cancer vaccine efficacy}

It is becoming clear that the immune response may be hindered by the hurdles created by tumors to evade the immune system. As noted, VEGF and other tumor-derived factors can inhibit DC 
maturation, and maturation of DCs ex vivo can circumvent this roadblock. We also discussed under "Peptide vaccines" (above) the use of cytokines, chemokines, and costimulatory molecules to activate and direct the immune response toward the appropriate type, as well as epitope enhancement to improve binding of tumor antigen epitopes to MHC molecules or TCRs.

Another area generating much recent interest is the possibility of overcoming mechanisms that downregulate or attenuate the immune response (Figure 4). Such mechanisms may have evolved to reduce inflammation and immunopathology or to prevent autoimmunity. Tumors have co-opted these mechanisms to evade immunosurveillance. T cells themselves express inhibitory receptors, the best studied being CTLA-4 $(111,112)$. This binds costimulatory molecules CD80 and CD86, but, instead of activating the T cell, dampens its response. Blockade of CTLA- 4 has been shown to improve tumor immunosurveillance and amplify effects of cancer vaccines in animals $(14,111)$. Recently, monoclonal anti-CTLA-4 antibodies have been studied in clinical trials alone or in conjunction with cancer vaccines (62). A substantial number of objective responses were found in a melanoma trial, but not without a number of autoimmune side effects, all reversed when therapy was stopped.

Another regulatory mechanism is the $\mathrm{CD} 25^{+} \mathrm{CD} 4^{+}$regulatory $\mathrm{T}$ cell $(15,17,113)$. Such cells are induced by antigens, especially in the presence of high IL-2 levels, but their effector activity is not antigen-specific (113). Blockade or elimination of these cells has been shown to enhance tumor immunosurveillance and efficacy of antitumor vaccines (15). Furthermore, concurrent blockade of $\mathrm{CD} 25^{+} \mathrm{CD} 4^{+}$regulatory $\mathrm{T}$ cells and of CTLA- 4 was synergistic in augmenting efficacy of a cancer vaccine (16).
Another novel immunoregulatory cell is the CD4 ${ }^{+}$NKT cell. These are $\mathrm{T}$ lymphocytes that share certain markers with NK cells but also express normal CD3 and $\alpha \beta$ TCRs. However, the TCRs used are limited to a few types that predominantly recognize glycolipids presented by a nonclassical class I MHC molecule, CD1d (114). These cells play a role in regulating immune responses causing autoimmune diseases, such as diabetes (115). Recently, we found that CD4 ${ }^{+}$NKT cells also can inhibit tumor immunosurveillance in a mouse fibrosarcoma model (17-19) and an orthotopic breast cancer model (116), and have now extended these findings to a non-regressor colon cancer model (19) (Park et al., unpublished results) (Figure 4). Elimination of NKT cells, or blockade of their effector mechanisms, such as IL-13 or downstream TGF- $\beta$, prevented tumor recurrence (17-19) and improved CTL responses and antiviral efficacy of a peptide AIDS vaccine in mice (52). Whereas regulatory NKT cells express predominantly Th2 cytokines, other NKT cells making IFN- $\gamma$ can actually contribute to tumor immunosurveillance (17). Factors influencing these opposing roles of NKT cells are under study. Thus, we propose that blockade of NKT cell negative regulatory cytokines can be used as a strategy to increase the efficacy of anticancer vaccines (17).

A complementary approach is to selectively induce high avidity CTLs $(4,117)$, which were first shown to be more effective at clearing virus infections (118) and then also to be more effective at killing tumor cells and eradicating tumors $(119,120)$. We recently found that increasing levels of costimulation, using a triad of costimulatory molecules - CD80, ICAM-1 and LFA-3 - in conjunction with a vaccine, can selectively induce CTLs skewed toward higher avidity and more effective at killing tumor cells (67). More-

\section{A Regulation through direct contact}

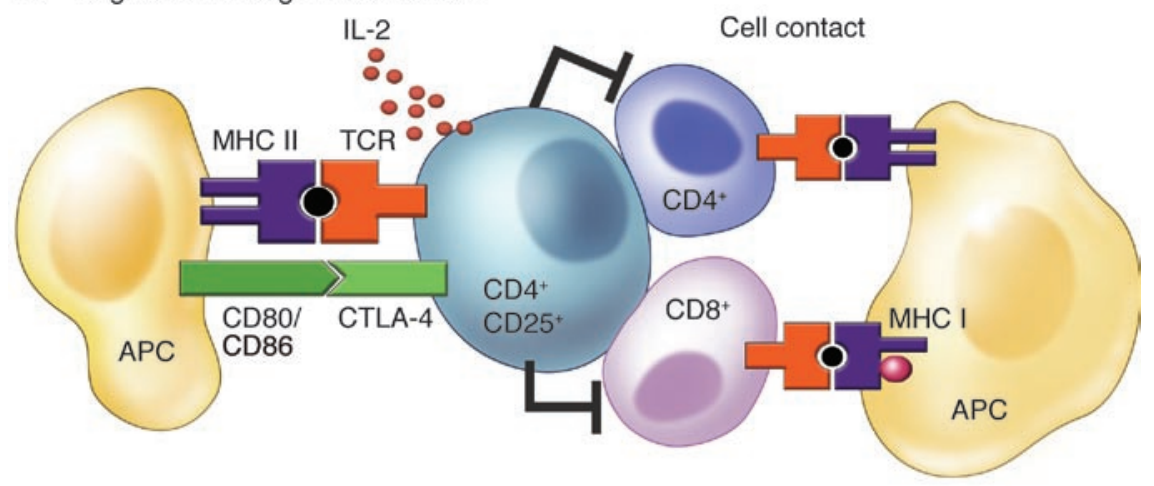

B Regulation by NKT cells, IL-13, TGF- $\beta$, and myeloid cells
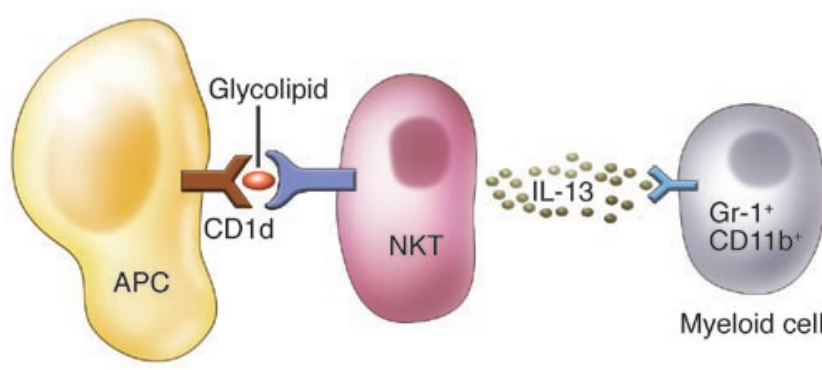

Myeloid cell

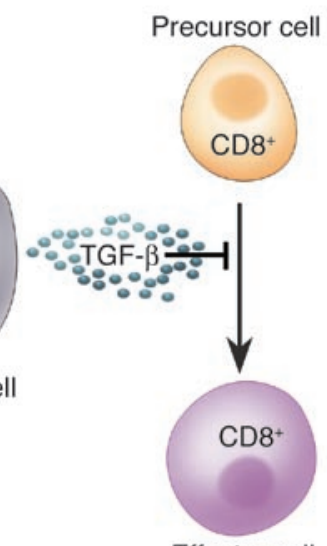

by Nancy Heim, Columbia University
Effector cell

\section{Figure 4}

Negative regulation of tumor immunosurveillance and antitumor immune responses. (A) CD4 ${ }^{+}$CD25 ${ }^{+} \mathrm{T}$ regulatory cells, induced by peptide presented by class II MHC molecules in the presence of IL-2, may inhibit induction of effector $\mathrm{CD}^{+}{ }^{+}$or $\mathrm{CD} 8^{+} \mathrm{T}$ cells by a contactdependent or cytokine-dependent mechanism, possibly involving cell surface and/or secreted TGF- $\beta$. (B) CD4+ NKT cells may be induced by tumor glycolipid presented by CD1d to secrete IL-13, which stimulates $\mathrm{Gr}-1+\mathrm{CD} 11 \mathrm{~b}+$ myeloid cells to produce TGF- $\beta$, which inhibits induction of CD8 ${ }^{+}$CTLs mediating tumor immunosurveillance. TGF- $\beta$ may also inhibit $\mathrm{CD} 4^{+} \mathrm{T}$ cells (not shown). Blockade of either mechanism can improve immunosurveillance and the response to vaccines. Other suppressor or negative regulatory cells have been described in other contexts but not as well studied in the context of cancer. 
over, IL-15 expressed by a vaccine has also been found to selectively induce longer-lived CTLs that may be more effective (121) and also a higher average avidity of CTLs (Oh et al., unpublished results). Indeed, we suggest that the recently discussed role of $\mathrm{CD}^{+} \mathrm{T}$ cell help and signal strength in inducing long-lived memory $\mathrm{CD}^{+}$ CTLs (122-125) may be mediated in part by helper cell stimulation of DCs to produce IL-15 when they present antigen to CTLs, as we have mimicked with IL-15 in the vaccine (121). These strategies may be useful in optimizing anticancer vaccines.

\section{Conclusion}

As prophylaxis against acute infectious diseases, vaccines have been among the most cost-effective agents, saving many millions of lives. However, for treatment of chronic infections and cancer, vaccines have yet to achieve widespread success. Increased understanding of the immune system has raised new hope of harnessing the exqui- site specificity of the immune system to attack cancer and has led to novel second-generation vaccine approaches that hold promise to control or cure cancer. The pace of identification of new tumor antigens has accelerated. New strategies are being developed to make more potent vaccines against inherently weak tumor antigens, to selectively induce high avidity CTLs more effective at clearing tumors, and to overcome negative regulatory mechanisms that inhibit tumor immunosurveillance and immune responses to antitumor vaccines. A number of promising new cancer vaccine strategies have entered clinical trials, and we eagerly await their findings.

Address correspondence to: Jay A. Berzofsky, Vaccine Branch, Center for Cancer Research, National Cancer Institute, National Institutes of Health, Building 10, Room 6B-12, 10 Center Drive (MSC\#1578), Bethesda, Maryland 20892-1578, USA. Phone: (301) 496-6874; Fax: (301) 480-0681; E-mail: berzofsk@helix.nih.gov.
1. Henderson, R.A., and Finn, O.J. 1996. Human tumor antigens are ready to fly. Adv. Immunol. 62:217-256

2. Disis, M.L., and Cheever, M.A. 1996. Oncogenic proteins as tumor antigens. Curr. Opin. Immunol. 8:637-642

3. Wang, R.-F., and Rosenberg, S.A. 1999. Human tumor antigens for cancer vaccine development. Immunol. Rev. 170:85-100.

4. Berzofsky, J.A., Ahlers, J.D., and Belyakov, I.M. 2001. Strategies for designing and optimizing new generation vaccines. Nat. Rev. Immunol. 1:209-219.

5. Yu, Z., and Restifo, N.P. 2002. Cancer vaccines: progress reveals new complexities. J. Clin. Invest. 110:289-294. doi:10.1172/JCI200216216.

6. Parmiani, G., et al. 2002. Cancer immunotherapy with peptide-based vaccines: what have we achieved? where are we going? J. Natl. Cancer. Inst. 94:805-818.

7. Salit, R.B., Kast, W.M., and Velders, M.P. 2002. Ins and outs of clinical trials with peptide-based vaccines. Front. Biosci. 7:e204-e213.

8. Berzofsky, J.A., and Berkower, I.J. 2003 Immunogenicity and antigen structure. In Fundamental immunology. W.E. Paul, editor. Lippincott Williams \& Wilkins. Philadelphia, Pennsylvania, USA. 631-683.

9. Germain, R.N., and Margulies, D.H. 1993. The biochemistry and cell biology of antigen processing and presentation. Annu. Rev. Immunol. 11:403-450.

10. Rosenberg, A.S., and Singer, A. 1992. Cellular basis of skin allograft rejection: an in vivo model of immune-mediated tissue destruction. Ann. Rev. Immunol. 10:333-358.

11. Waldmann, T.A. 2003. Immunotherapy: past, present and future. Nat. Med. 9:269-277.

12. Hung, K., et al. 1998. The central role of CD4(+) $\mathrm{T}$ cells in the antitumor immune response. J. Exp. Med. 188:2357-2368.

13. Banchereau, J., and Steinman, R.M. 1998. Dendritic cells and the control of immunity. Nature. 392:245-252.

14. Hurwitz, A.A., Yu, T.F.-Y., Leach, D.R., and Allison, J.P. 1998. CTLA-4 blockade synergizes with tumorderived granulocyte-macrophage colony-stimulating factor for treatment of an experimental mammary carcinoma. Proc. Natl. Acad. Sci. U. S. A 95:10067-10071.

15. Shimizu, J., Yamazaki, S., and Sakaguchi, S. 1999. Induction of tumor immunity by removing CD25+ CD4+ T cells: a common basis between tumor immunity and autoimmunity. J. Immunol. 163:5211-5218.

16. Sutmuller, R.P.M., et al. 2001. Synergism of cytotoxic T lymphocyte-associated antigen 4 blockade and depletion of CD25+ regulatory T cells in antitumor therapy reveals alternative cytotoxic $\mathrm{T}$ lymphocyte responses. J. Exp. Med. 194:823-832.

17. Terabe, M., and Berzofsky, J.A. 2004. Immunoregulatory $\mathrm{T}$ cells in tumor immunity. Curr. Opin. Immunol. 16:157-162.

18. Terabe, M., et al. 2000. NKT cell-mediated repression of tumor immunosurveillance by IL-13 and the IL-4R-STAT6 pathway. Nat. Immunol. 1:515-520.

19. Terabe, M., et al. 2003. Transforming growth factor- $\beta$ production and myeloid cells are an effector mechanism through which CD1d-restricted T cells block cytotoxic T lymphocyte-mediated tumor immunosurveillance: abrogation prevents tumor recurrence. J. Exp. Med. 198:1741-1752.

20. Renkvist, N., Castelli, C., Robbins, P.F., and Parmiani, G. 2001. A listing of human tumor antigens recognized by T cells. Cancer Immunol. Immunother. 50:3-15.

21. Berzofsky, J.A., Helman, L.J., and Carbone, D.P. 2000. Cancer vaccines: cancer antigens: oncogenes and mutations. In Principles and practice of the biologic therapy of cancer. 3rd edition. S.A. Rosenberg, editor. Lippincott Williams \& Wilkins. Philadelphia, Pennsylvania, USA. 526-541.

22. Gjertsen, M.K., et al. 1995. Vaccination with mutant ras peptides and induction of $\mathrm{T}$-cell responsiveness in pancreatic carcinoma patients carrying the corresponding RAS mutation. Lancet. 346:1399-1400.

23. Yanuck, M., et al. 1993. A mutant p53 tumor suppressor protein is a target for peptide-induced CD8+ cytotoxic T cells. Cancer Res. 53:3257-3261.

24. Pinilla-Ibarz, J., et al. 2000. Vaccination of patients with chronic myelogenous leukemia with bcr-abl oncogene breakpoint fusion peptides generates specific immune responses. Blood. 95:1781-1787.

25. Goletz, T.J., Mackall, C.L., Berzofsky, J.A., and Helman, L.J. 1998. Molecular alterations in pediatric sarcomas: potential targets for immunotherapy. Sarcoma. 2:77-87.

26. Mackall, C., Berzofsky, J., and Helman, L.J. 2000. Targeting tumor specific translocations in sarcomas in pediatric patients for immunotherapy. Clin. Orthop. 25-31.

27. Worley, B.S., et al. 2001. Antigenicity of fusion proteins from sarcoma-associated chromosomal translocations. Cancer Res. 61:6868-6875.

28. Bos, J.L. 1989. ras oncogenes in human cancer: a review. Cancer Res. 49:4682-4689.

29. Chiba, I., et al. 1990. Mutations in the 553 gene are frequent in primary, resected non-small cell lung cancer. Oncogene. 5:1603-1610.

30. Smith, M.C., et al. 1997. Oncogenic mutations in ras create HLA-A2.1 binding peptides but affect their extracellular processing. Int. Immunol. 9:1085-1093.

31. Peace, D.J., et al. 1994. Lysis of Ras oncogene-trans- formed cells by specific cytotoxic T lymphocytes elicited by primary in vitro immunization with mutated Ras peptide. J. Exp. Med. 179:473-479.

32. Zaremba, S., et al. 1997. Identification of an enhancer agonist cytotoxic $\mathrm{T}$ lymphocyte peptide from human carcinoembryonic antigen. Cancer Res. 57:4570-4577.

33. Fong, L., et al. 2001. Altered peptide ligand vaccination with Flt3 ligand expanded dendritic cells for tumor immunotherapy. Proc. Natl. Acad. Sci. U. S. A. 98:8809-8814.

34. Theobald, M., Biggs, J., Dittmer, D., Levine, A.J., and Sherman, L.A. 1995. Targeting p53 as a general tumor antigen. Proc. Natl. Acad. Sci. U. S. A. 92:11993-11997.

35. Correale, P., et al. 1997. In vitro generation of human cytotoxic $\mathrm{T}$ lymphocytes specific for peptides derived from prostate-specific antigen. J. Natl. Cancer Inst. 89:293-300.

36. Roskrow, M.A., et al. 1998. Epstein-Barr virus (EBV)-specific cytotoxic $\mathrm{T}$ lymphocytes for the treatment of patients with EBV-positive relapsed Hodgkin's disease. Blood. 91:2925-2934.

37. Dranoff, G., et al. 1993. Vaccination with irradiated tumor cells engineered to secrete murine granulocyte-macrophage colony-stimulating factor stimulates potent, specific, and long-lasting anti-tumor immunity. Proc. Natl. Acad. Sci. U.S.A. 90:3539-3543.

38. Simons, J.W., et al. 1999. Induction of immunity to prostate cancer antigens: results of a clinical trial of vaccination with irradiated autologous prostate tumor cells engineered to secrete granulocyte-macrophage colony-stimulating factor using ex vivo gene transfer. Cancer Res. 59:5160-5168.

39. Soiffer, R., et al. 1998. Vaccination with irradiated autologous melanoma cells engineered to secrete human granulocyte-macrophage colony-stimulating factor generates potent antitumor immunity in patients with metastatic melanoma. Proc. Natl. Acad. Sci. U. S. A. 95:13141-13146.

40. Jaffee, E.M., et al. 2001. Novel allogeneic granulocyte-macrophage colony-stimulating factor-secreting tumor vaccine for pancreatic cancer: a phase I trial of safety and immune activation. J. Clin. Oncol. 19:145-156.

41. Salgia, R., et al. 2003. Vaccination with irradiated autologous tumor cells engineered to secrete granulocyte-macrophage colony-stimulating factor augments antitumor immunity in some patients with metastatic non-small-cell lung carcinoma. J. Clin. Oncol. 21:624-630.

42. Maio, M., et al. 2002. Vaccination of stage IV patients with allogeneic IL-4- or IL-2-gene-transduced melanoma cells generates functional antibodies against vaccinating and autologous melanoma cells. Cancer 
Immunol. Immunother. 51:9-14.

43. Antonia, S.J., et al. 2002. Phase I trial of a B7-1 (CD80) gene modified autologous tumor cell vaccine in combination with systemic interleukin-2 in patients with metastatic renal cell carcinoma. J. Urol. 167:1995-2000

44. Unfer, R.C., Hellrung, D., and Link, C.J., Jr. 2003. Immunity to the alpha $(1,3)$ galactosyl epitope provides protection in mice challenged with colon cancer cells expressing alpha $(1,3)$ galactosyl-transferase: a novel suicide gene for cancer gene therapy. Cancer Res. 63:987-993.

45. Stern, L.J., and Wiley, D.C. 1994. Antigenic peptide binding by class I and class II histocompatibility proteins. Structure. 2:245-251.

46. Rammensee, H.-G., Friede, T., and Stevanovíc, S. 1995. MHC ligands and peptide motifs: first listing. Immunogenetics. 41:178-228.

47. Traversari, C., et al. 1992. A nonapeptide encoded by human gene MAGE- 1 is recognized on HLA-A1 by cytolytic $\mathrm{T}$ lymphocytes directed against tumor antigen MZ2-E. J. Exp. Med. 176:1453-1457.

48. Berzofsky, J.A. 1993. Epitope selection and design of synthetic vaccines: molecular approaches to enhancing immunogenicity and crossreactivity of engineered vaccines. Ann. N. Y. Acad. Sci. 690:256-264.

49. Rosenberg, S.A., et al. 1998. Immunologic and therapeutic evaluation of a synthetic peptide vaccine for the treatment of patients with metastatic melanoma. Nat. Med. 4:321-327.

50. Rivoltini, L., et al. 1999. A superagonist variant of peptide MART1/Melan A27-35 elicits antimelanoma CD8+ T cells with enhanced functional characteristics: implication for more effective immunotherapy. Cancer Res. 59:301-306.

51. Brinckerhoff, L.H., et al. 1999. Terminal modifications inhibit proteolytic degradation of an immunogenic MART-1(27-35) peptide: implications for peptide vaccines. Int. J. Cancer. 83:326-334.

52. Ahlers, J.D., et al. 2002. A push-pull approach to maximize vaccine efficacy: abrogating suppression with an IL-13 inhibitor while augmenting help with GM-CSF and CD40L. Proc. Natl. Acad. Sci. U. S. A. 99:13020-13025.

53. Klinman, D.M., Yi, A.K., Beaucage, S.L., Conover, J., and Krieg, A.M. 1996. CpG motifs present in bacterial DNA rapidly induce lymphocytes to secrete interleukin 6, interleukin 12, and interferon gamma. Proc. Natl. Acad. Sci. U. S. A. 93:2879-2883.

54. Alexander, J., et al. 1994. Development of high potency universal DR-restricted helper epitopes by modification of high affinity DR-blocking peptides. Immunity. 1:751-761.

55. Shirai, M., et al. 1996. Use of intrinsic and extrinsic helper epitopes for in vivo induction of anti-hepatitis $\mathrm{C}$ virus cytotoxic T lymphocytes (CTL) with CTL epitope peptide vaccines. J. Infect. Dis. 173:24-31.

56. Melief, C.J., Van Der Burg, S.H., Toes, R.E., Ossendorp, F., and Offringa, R. 2002. Effective therapeutic anticancer vaccines based on precision guiding of cytolytic T lymphocytes. Immunol. Rev. 188:177-182.

57. Ahlers, J.D., Belyakov, I.M., Thomas, E.K., and Berzofsky, J.A. 2001. High affinity T-helper epitope induces complementary helper and APC polarization, increased CTL and protection against viral infection. J. Clin. Invest. 108:1677-1685. doi:10.1172/JCI200113463.

58. Smith, J.W., 2nd, et al. 2003. Adjuvant immunization of HLA-A2-positive melanoma patients with a modified gp100 peptide induces peptide-specific CD8+ T-cell responses. J. Clin. Oncol. 21:1562-1573.

59. Lee, P., et al. 2001. Effects of interleukin-12 on the immune response to a multipeptide vaccine for resected metastatic melanoma. J. Clin. Oncol. 19:3836-3847.

60. Weber, J., et al. 2003. Granulocyte-macrophagecolony-stimulating factor added to a multipeptide vaccine for resected Stage II melanoma. Cancer.
97:186-200.

61. Schaed, S.G., et al. 2002. T-cell responses against tyrosinase 368-376(370D) peptide in HLA*A0201+ melanoma patients: randomized trial comparing incomplete Freund's adjuvant, granulocyte macrophage colony-stimulating factor, and QS-21 as immunological adjuvants. Clin. Cancer Res. 8:967-972.

62. Phan, G.Q., et al. 2003. Cancer regression and autoimmunity induced by cytotoxic T lymphocyte-associated antigen 4 blockade in patients with metastatic melanoma. Proc. Natl. Acad. Sci. U. S. A . 100:8372-8377.

63. Marshall, J.L., et al. 2000. Phase I study in advanced cancer patients of diversified prime-and-boost vaccination protocol using recombinant vaccinia virus and recombinant nonreplicating avipox virus to elicit anti-carcinoembryonic antigen immune responses. J. Clin. Oncol. 18:3964-3973.

64. Zhu, M.Z., Marshall, J., Cole, D., Schlom, J., and Tsang, K.Y. 2000. Specific cytotoxic T-cell responses to human CEA from patients immunized with recombinant avipox-CEA vaccine. Clin. Cancer Res. 6:24-33.

65. Belyakov, I.M., Moss, B., Strober, W., and Berzofsky, J.A. 1999. Mucosal vaccination overcomes the barrier to recombinant vaccinia immunization caused by preexisting poxvirus immunity. Proc. Natl. Acad. Sci. U. S. A. 96:4512-4517.

66. Hodge, J.W., et al. 1999. A triad of costimulatory molecules synergize to amplify T-cell activation. Cancer Res. 59:5800-5807.

67. Oh, S., et al. 2003. Selective induction of high avidity CTL by altering the balance of signals from antigen presenting cells. J. Immunol. 170:2523-2530.

68. Tang, D., DeVit, M., and Johnston, S.A. 1992. Genetic immunization is a simple method for eliciting an immune response. Nature. 356:152-154.

69. Ulmer, J.B., et al. 1993. Heterologous protection against influenza by injection of DNA encoding a viral protein. Science. 259:1745-1749.

70. Timmerman, J.M., et al. 2002. Immunogenicity of a plasmid DNA vaccine encoding chimeric idiotype in patients with B-cell lymphoma. Cancer Res. 62:5845-5852.

71. Conry, R.M., et al. 2002. Safety and immunogenicity of a DNA vaccine encoding carcinoembryonic antigen and hepatitis B surface antigen in colorectal carcinoma patients. Clin. Cancer Res. 8:2782-2787.

72. Fong, L., and Engleman, E.G. 2000. Dendritic cells in cancer immunotherapy. Annu. Rev. Immunol. 18:245-273.

73. Schuler, G., Schuler-Thurner, B., and Steinman, R.M. 2003. The use of dendritic cells in cancer immunotherapy. Curr. Opin. Immunol. 15:138-147.

74. Gabrilovich, D.I., Nadaf, S., Corak, J., Berzofsky, J.A., and Carbone, D.P. 1996. Dendritic cells in antitumor immune responses. II. Dendritic cells grown from bone marrow precursors, but not mature DC from tumor-bearing mice are effective antigen carriers in the therapy of established tumors. Cell Immunol. 170:111-119.

75. Gabrilovich, D.I., et al. 1996. Production of vascular endothelial growth factor by human tumors inhibits the functional maturation of dendritic cells [erratum 1996, 2:1267]. Nat. Med. 2:1096-1103

76. Mayordomo, J.I., et al. 1995. Bone marrow-derived dendritic cells pulsed with synthetic tumour peptides elicit protective and therapeutic antitumour immunity. Nat. Med. 1:1297-1302.

77. Porgador, A., and Gilboa, E. 1995. Bone marrowgenerated dendritic cells pulsed with a class Irestricted peptide are potent inducers of cytotoxic T lymphocytes. J. Exp. Med. 182:255-260.

78. Nair, S.K., Snyder, D., Rouse, B.T., and Gilboa, E. 1997. Regression of tumors in mice vaccinated with professional antigen-presenting cells pulsed with tumor extracts. Int J. Cancer 70:706-715.

79. Paglia, P., Chiodoni, C., Rodolfo, M., and Colombo,
M.P. 1996. Murine dendritic cells loaded in vitro with soluble protein prime cytotoxic T lymphocytes against tumor antigen in vivo. J. Exp. Med. 183:317-322.

80. Zitvogel, L., et al. 1996. Therapy of murine tumors with tumor peptide-pulsed dendritic cells: dependence on T cells, B7 costimulation, and T helper cell 1-associated cytokines. J. Exp. Med. 183:87-97.

81. Ashley, D.M., et al. 1997. Bone marrow-generated dendritic cells pulsed with tumor extracts or tumor RNA induce antitumor immunity against central nervous system tumors. J. Exp. Med. 186:1177-1182.

82. Mayordomo, J.I., et al. 1996. Therapy of murine tumors with p53 wild-type and mutant sequence peptide-based vaccines. J. Exp. Med. 183:1357-1365.

83. Siders, W.M., Vergilis, K.L., Johnson, C., Shields, J., and Kaplan, J.M. 2003. Induction of specific antitumor immunity in the mouse with the electrofusion product of tumor cells and dendritic cells. Mol. Ther. 7:498-505.

84. Chen, H.W., et al. 2003. Inducing long-term survival with lasting anti-tumor immunity in treating $B$ cell lymphoma by a combined dendritic cell-based and hydrodynamic plasmid-encoding IL-12 gene therapy. Int. Immunol. 15:427-435.

85. Akiyama, Y., et al. 2000. Enhancement of antitumor immunity against B16 melanoma tumor using genetically modified dendritic cells to produce cytokines. Gene Ther. 7:2113-2121.

86. Wan, Y., Bramson, J., Carter, R., Graham, F., and Gauldie, J. 1997. Dendritic cells transduced with an adenoviral vector encoding a model tumor-associated antigen for tumor vaccination. Hum. Gene Ther. 8:1355-1363.

87. Esslinger, C., Romero, P., and MacDonald, H.R. 2002. Efficient transduction of dendritic cells and induction of a T-cell response by third-generation lentivectors. Hum. Gene Ther. 13:1091-1100.

88. Bonifaz, L., et al. 2002. Efficient targeting of protein antigen to the dendritic cell receptor DEC-205 in the steady state leads to antigen presentation on major histocompatibility complex class I products and peripheral CD8+ T cell tolerance. J. Exp. Med. 196:1627-1638.

89. Caux, C., Dezutter-Dambuyant, C., Schmitt, D., and Banchereau, J. 1992. GM-CSF and TNF-alpha cooperate in the generation of dendritic Langerhans cells. Nature. 360:258-261.

90. Sallusto, F., and Lanzavecchia, A. 1994. Efficient presentation of soluble antigen by cultured human dendritic cells is maintained by granulocyte/macrophage colony-stimulating factor plus interleukin 4 and downregulated by tumor necrosis factor $\alpha$. J. Exp. Med. 179:1109-1118.

91. Banchereau, J., et al. 2001. Immune and clinical responses in patients with metastatic melanoma to CD34(+) progenitor-derived dendritic cell vaccine. Cancer Res. 61:6451-6458.

92. Mackensen, A., et al. 2000. Phase I study in melanoma patients of a vaccine with peptide-pulsed dendritic cells generated in vitro from CD34(+) hematopoietic progenitor cells. Int. J. Cancer. 86:385-392.

93. Rosenzwajg, M., Jourquin, F., Tailleux, L., and Gluckman, J.C. 2002. CD40 ligation and phagocytosis differently affect the differentiation of monocytes into dendritic cells. J. Leukoc. Biol. 72:1180-1189.

94. Labeur, M.S., et al. 1999. Generation of tumor immunity by bone marrow-derived dendritic cells correlates with dendritic cell maturation stage. J. Immunol. 162:168-175.

95. Dhodapkar, M.V., Steinman, R.M., Krasovsky, J., Munz, C., and Bhardwaj, N. 2001. Antigen-specific inhibition of effector $\mathrm{T}$ cell function in humans after injection of immature dendritic cells. J. Exp. Med. 193:233-238.

96. Dhodapkar, M.V., and Steinman, R.M. 2002. 
Antigen-bearing immature dendritic cells induce peptide-specific CD8 $(+)$ regulatory $\mathrm{T}$ cells in vivo in humans. Blood. 100:174-177.

97. Jonuleit, H., Schmitt, E., Schuler, G., Knop, J., and Enk, A.H. 2000. Induction of interleukin 10-producing, nonproliferating CD4(+) T cells with regulatory properties by repetitive stimulation with allogeneic immature human dendritic cells. J. Exp. Med. 192:1213-1222.

98. Steinmann, R.M., and Dhodapkar, K. 2001. Active immunization against cancer with dendritic cells. Int. J. Cancer. 94:459-573.

99. Nestle, F.O. 2000. Dendritic cell vaccination for cancer therapy. Oncogene. 19:6673-6679.

100.Hsu, F.J., et al. 1996. Vaccination of patients with B-cell lymphoma using autologous antigen-pulsed dendritic cells. Nat. Med. 2:52-58.

101.Timmerman, J.M., et al. 2002. Idiotype-pulsed dendritic cell vaccination for B-cell lymphoma: clinical and immune responses in 35 patients. Blood. 99:1517-1526.

102. Reichardt, V.L., et al. 1999. Idiotype vaccination using dendritic cells after autologous peripheral blood stem cell transplantation for multiple myeloma-a feasibility study. Blood. 93:2411-2419.

103.Liso, A., et al. 2000. Idiotype vaccination using dendritic cells after autologous peripheral blood progenitor cell transplantation for multiple myeloma. Biol. Blood Marrow Transplant. 6:621-627.

104.Valone, F.H., et al. 2001. Dendritic cell-based treatment of cancer: closing in on a cellular therapy. Cancer J. 7(Suppl. 2):S53-S61.

105.Fong, L., et al. 2001. Dendritic cell-based xenoantigen vaccination for prostate cancer immunotherapy. J. Immunol. 167:7150-7156.

106. Nestle, F.O., et al. 1998. Vaccination of melanoma patients with peptide- or tumor lysate-pulsed dendritic cells. Nat. Med. 4:328-332.

107. Thurner, B., et al. 1999. Vaccination with mage-3A1 peptide-pulsed mature, monocyte-derived dendritic cells expands specific cytotoxic T cells and induces regression of some metastases in advanced stage IV melanoma. J. Exp. Med. 190:1669-1678.

108.Stift, A., et al. 2003. Dendritic cell-based vaccination in solid cancer. J. Clin. Oncol. 21:135-142.

109.Su, Z., et al. 2003. Immunological and clinical responses in metastatic renal cancer patients vaccinated with tumor RNA-transfected dendritic cells. Cancer Res. 63:2127-2133.

110.Serody, J.S., Collins, E.J., Tisch, R.M., Kuhns, J.J., and Frelinger, J.A. 2000. T cell activity after dendritic cell vaccination is dependent on both the type of antigen and the mode of delivery. J. Immunol. 164:4961-4967.

111.Egen, J.G., Kuhns, M.S., and Allison, J.P. 2002. CTLA-4: new insights into its biological function and use in tumor immunotherapy. Nat. Immunol. 3:611-618.

112.Lee, K.M., et al. 1998. Molecular basis of T cell inactivation by CTLA-4. Science. 282:2263-2266.

113.Thornton, A.M., and Shevach, E.M. 2000. Suppressor effector function of CD4+CD25+ immunoregulatory $\mathrm{T}$ cells is antigen nonspecific. J. Immunol. 164:183-190.

114.Kronenberg, M., and Gapin, L. 2002. The unconventional lifestyle of NKT cells. Nat. Rev. Immunol. 2:557-568.

115.Wilson, S.B., and Delovitch, T.L. 2003. Janus-like role of regulatory iNKT cells in autoimmune disease and tumour immunity. Nat. Rev. Immunol. 3:211-222.

116. Ostrand-Rosenberg, S., et al. 2002. Resistance to metastatic disease in Stat6-deficient mice requires hematopoietic and non-hematopoietic cells and is
IFN $\gamma$-dependent. J. Immunol. 169:5796-5804.

117. Snyder, J.T., Alexander-Miller, M.A., Berzofsky, J.A., and Belyakov, I.M. 2003. Molecular mechanisms and biological significance of CTL avidity. Curr. HIV Res. 1:287-294.

118. Alexander-Miller, M.A., Leggatt, G.R., and Berzofsky, J.A. 1996. Selective expansion of high or low avidity cytotoxic T lymphocytes and efficacy for adoptive immunotherapy. Proc. Natl. Acad. Sci. U. S. A. 93:4102-4107.

119.Yee, C., Savage, P.A., Lee, P.P., Davis, M.M., and Greenberg, P.D. 1999. Isolation of high avidity melanoma-reactive CTL from heterogeneous populations using peptide-MHC tetramers. J. Immunol. 162:2227-2234

120.Zeh, H.J., III, Perry-Lalley, D., Dudley, M.E., Rosenberg, S.A., and Yang, J.C. 1999. High avidity CTLs for two self-antigens demonstrate superior in vitro and in vivo antitumor efficacy. J. Immunol. 162:989-994.

121. Oh, S., Berzofsky, J.A., Burke, D.S., Waldmann, T.A., and Perera, L.P. 2003. Coadministration of HIV vaccine vectors with vaccinia viruses expressing IL-15 but not IL-2 induces long-lasting cellular immunity. Proc. Natl. Acad. Sci. U. S. A. 100:3392-3397.

122.Janssen, E.M., et al. 2003. CD4+ T cells are required for secondary expansion and memory in CD8+ T lymphocytes. Nature. 421:852-856.

123.Sun, J.C., and Bevan, M.J. 2003. Defective CD8 T cell memory following acute infection without CD4 T cell help. Science. 300:339-342.

124.Shedlock, D.J., and Shen, H. 2003. Requirement for CD4 T cell help in generating functional CD8 T cell memory. Science. 300:337-339.

125.Gett, A.V., Sallusto, F., Lanzavecchia, A., and Geginat, J. 2003. T cell fitness determined by signal strength. Nat. Immunol. 4:355-360. 